ich überhaupt eigentlich in keinem Fall von Cocceneiter bemerken köınen. Es war nur ein zarter Hauch von Rot zu sehen, so zart nitunter, daß man ihn bei nicht ganz aufmerksamer Betrachtung oder bei ulıgünstiger Beleuchtung wohl übersehen konnte. Ebenso unsicher ist das zweite líriterium, die Konsistenz des Eiterhäutehens oder besser Eiterklümpchens. Ein „zerfließliches“ Häutchen habe ich unter allen Cocceneiterfällen nur zweimal, bei einell Staphylococcenund einom Pneumococceneiter beobachtet. Sonst kanı es immer zur Bildung eines zusammenhängenden Häutchens oder Klïmp. chens, das bald inehr, bald weniger leicht beim Anstoßen zerbröckelte. Ia, in nicht weniger als fünf Fällen von Cocceneiter war die Konsistenz des Häutchens so fest, dal man es, ohne dab es zerbrach, init einer Platinnadel emporheben konnte. Bleibt dann außerdem noch eine deutliche Rötung des Reagens aus, wie in dreien dieser Fälle, so läßat die Methode vollständig in Stich und führt sogar irre. Die Verwendbarkeit der Me-

Aus dem Pathologischen Institut der Universität in Tübingen. (Direktor: Prof. Dr. P. v. Baumgarten.)

\section{Ist das Müllersche Verfahren der Unter- scheidung des tuberkulösen Eiters von Cocceneiter mittels des Millonschen Reagens brauchbar?}

Von Dr. Hermann Dold, Assistent am Institut.

Die interessanten Arbeiten von Jochmann ${ }^{2}$ ), Müllor $r^{4,3}$, und Kolaczek ${ }^{3}$ ) liaben gezeigt, dab Cocceneiter und tuberkulöser Eiter eine verschiedene proteolytische Fähigkeit besitzen, daß diese proteolytische Fähigkeit an die polynukleären Leukocyten gebunden ist und $\mathrm{daB}$ sich diese Verschiedenheit im Verhalten der beiden genannten Eiterarten zu ihrer Unterscheidung verwerten läßjt. Wenn man nämlich nuf die Oberfläche einer Löffler'serumplatte einige Tröpfichen Eiter bringt, so tritt bei rein tuberkulösem Eiter keine Verdauung (keine Delle) ein, wohl aber bei allen anderen Eitersorten. Da aber diese Methode einen Brutschrank und Serumplatten erfordert, so jst ihre Anwendung naturgemäl auf Krankenhäuser und Klinikeı beschränkt. Nun hat Müller, um auch den Anforderungen des Praktikers zu dienen, ein neues, einfaches, „chemischphysikalisches" "Verfahren zur Unterscheidung von tuberkulösem und andersartigem Eiter ausgearbeitet und im Zentralblatt für innere Medizin 1907, No. 12 sowie in dieser Wochenschrift 1907, No. 17 beschrieben. Wonn man kleine Porzellanschälchen mit Millons Reagens füllt uld dann einell oder zwei 'Tropfen Witer auftropft, so soll der rein tuberkulöse Eiter' ein zähes Häutchen bilden und die Millon sche Reagenzflüssigkeit ungefärbt bleiben, während die übrigen Eitersorten eine zerfliebliche Scheibe bilden und das Millonsche Reagens leblıaft röten sollen.

Ich habe das Verfahren an dem Eiter, der uns aus del Kliniken zur bakteriologischen Untersuchung regelmäßig zugoht, nachgeprüft und nunmelir 30 Eiterprobell verschiedener Herkunft in der angegebenen Weise untersucht und mit dem mikroskopischen und kulturellen Befund verglichen. Im ganzen waren es 10 Fällc von tuberkulösem Eiter, 13 Fälle von Staphylound Streptococceneiter, 4 Fälle von Pneumococceneiter und 3 Fälle von Coli- und Jocceneiter. Die Ergebnisse dieser Untersuchungen, die ich hiermit, ohne auf die theoretische Seite der Sache einzugehen, kurz mitteilen möchte, stimmen leider mit den Angaben von Müller nicht überein. In allen elf Fällen von rein tuberkulösem Eitèr blieb zwar - entsprechend den Angaben von Müller --- das Millonsche Reagens ungefärbt, und es bildete sich ein zähes, festes Häutchen. Aber in 4 von den 13 Fällen von Staphylo- und Streptococceneiter blieb das Millonsche Reagens ebenfalls ungefärbt, ebenso einmal bei den Pneumococceneiterfällen und einmal bei den Colieiterfällen. Eine "lebhafte Rotfärbung" des Millonschen Reagens habe

2) Ueber eine einfache Methode zum Nachwe is proteolytischer Fermentwirkungen. .Hünchener medizinische Woclienschrift 19\%, No. 23, wad Ueber proteolytische Fermentwirkungen der Leukocyten. Münchener medizinische Wochenschrift 1906, No. 3h.3) Veber ein einfaches Hilfs inittel zur Unterscheidung tuberkuloser und andersartiger Eiterungen. Deutsches Hilismittel zur Unterscheifung tuberku. thode erloidet außerdem dadurch eine häufige Einschränkung, daß Init Blut untermischter Eiter sowie klumpiger Eiter nicht gut brauchbar ist. Bei letzterem kann man zwar durch Zusatz von steriler, physiologischer Kochsalzlösung und kräftiges Umschütteln eine Verflüssigung herbeiführen, aber diese Manipulation erfordert auch wieder Zeit. Und da man llach Müllers Angabe eine Viertelstunde zuwarten mub, un oinen sicheren Entscheid über den Ausgang der Reaktion treffon zu können, so ist zu bemerken, da man in den meisten Fällon innerhalb dioser Zeit mit Leichtigkeit aus einen Ausstrichprïparat direkt den cytologischen und bakteriologischen Befund erheben kann.

Zusammenfassung. Nach alledem kann man m. E. das Mïllersche Verfahren der Unterscheidung tuberkulösen Eiters von andersartigem Eiter mittels des Millon schen Reagens nicht als zuverlässig und für den Praktiker brauchbar bezeichnen. 